\title{
As Tecnologias Digitais e os Professores do Ensino Médio: Formação para o uso do Tablet Educacional
}

\author{
Elivelton Henrique Gonçalves ${ }^{1}$, Fernanda de Oliveira Costa ${ }^{2}$, \\ Adelma L.O.S. Araújo ${ }^{3}$ \\ ${ }^{1}$ Universidade Federal de Uberlândia - Uberlândia - MG - Brasil \\ ${ }^{2}$ Universidade Federal de Ouro Preto - Ouro Preto - MG - Brasil \\ ${ }^{3}$ Universidade Federal de Minas Gerais - Belo Horizonte - MG - Brasil \\ eliveltonhg@hotmail.com, ferolivercosta@gmail.com, \\ adelmaa.ufmg@gmail.com
}

\begin{abstract}
In this paper we addressed the training of High School teachers, a school which is member of State Education System from in the State of Minas Gerais, for the use of Educational Tablet. The Educational Tablet was given to the teachers this school in mid-2013, however they were not using it, due difficulties in handling it. Thus, this study aimed at understanding the importance of continuous development of these teachers as a possibility of include Educational Tablet in their pedagogical proposals. The research, accomplished by Action-Research, showed that the use of Educational Tablet as a teaching-learning tool will depend largely on the actions developed for the training of teachers who will use it.
\end{abstract}

Resumo. No presente artigo é abordada a formação de professores do ensino médio, de uma escola integrante da Rede Estadual de Ensino do Estado de Minas Gerais, para o uso do Tablet Educacional. Os aparelhos foram entregues aos professores dessa escola em meados de 2013, contudo, eles não estavam utilizando-o, por dificuldades em manuseá-lo. Desse modo, o objetivo deste estudo é compreender a importância da formação contínua desses professores como uma possibilidade de inclusão do aparelho em suas propostas pedagógicas. A pesquisa, realizada por meio da Pesquisa-Ação, evidenciou que o uso do Tablet Educacional, como uma ferramenta de ensinoaprendizagem, dependerá, em grande parte, das ações desenvolvidas para a formação dos professores que irão utilizá-lo.

\section{Introdução}

$\mathrm{Na}$ sociedade contemporânea estamos rodeados pelas novas tecnologias, as quais influenciam de forma significativa nossas vidas, desde a formação e interação sociocultural até a maneira de aquisição de novos conhecimentos. Diante dos avanços crescentes das tecnologias, a produção, disseminação e acesso às informações estão acontecendo de maneira rápida, motivada, parcialmente, pelo desenvolvimento dos sistemas informacionais e pelo acesso da população a um grande aparato tecnológico (VELLOSO, 2014). Assim, há a necessidade de criar novos métodos, estratégias e práticas de aprender e ensinar, que contemplem o atual cenário tecnológico. 
Nesse contexto, a escola tem o desafio de ressignificar à prática pedagógica do seu corpo docente instigando-os a integrar as novas tecnologias no ambiente escolar. Segundo Quaresma et al. (2014), em uma sociedade que constantemente exige novas aprendizagens, o professor precisa estar preparado para rever conceitos, (re)construir concepções e superar paradigmas. A evolução das tecnologias provocou mudanças nas relações entre quem ensina e quem aprende. Ambos, professor e aluno, necessitam estabelecer constantes diálogos e uma incessante troca de conhecimentos.

Com a disseminação e popularização dos dispositivos móveis digitais, supõe-se que a maioria das pessoas tenha o mínimo de conhecimento para o manuseio desses instrumentos, mas essa não é uma realidade (BÉVORT; BELLONI, 2009). Neves e Cardoso (2013) afirmam que quando falamos das novas tecnologias digitais na Educação, um dos maiores desafios enfrentados pela maioria dos professores é adequarem suas práticas pedagógicas às características do mundo tecnológico, de modo a atenderem as novas gerações que frequentam as escolas. Prensky (2001, p. 2) complementa: "[...] nossos instrutores [...] que usam uma linguagem ultrapassada (da era pré-digital), estão lutando para ensinar a uma população que fala uma linguagem totalmente nova".

Nessa perspectiva, de modo a buscar o acompanhamento das mudanças tecnológicas, o Ministério da Educação (MEC), por meio do Programa ProInfo (Programa Nacional de Tecnologia Educacional), tem promovido a instrumentalização das escolas e dos professores com as novas tecnologias, de modo a possibilitar novas estratégias pedagógicas com o uso de conteúdos e recursos multimídias e digitais (FNDE, 2015). Uma das ações desenvolvidas pelo MEC, de acordo com Brasil (2012), é a distribuição de tablets, conhecidos como Tablet Educacional, aos professores do Ensino Médio das escolas públicas brasileiras. Oferecer o aparelho, uma tecnologia móvel, aos professores, defendem Neves e Cardoso (2013), significa uma maior mobilidade, acessibilidade e possibilidades didáticas e pedagógicas de utilização das Tecnologias da Informação e Comunicação (TIC) no dia a dia escolar.

Segundo Nascimento (2014), o aparelho ainda permite aos professores a exploração de novas possibilidades pedagógicas, conhecendo e vivenciando atividades a partir dos recursos disponíveis no equipamento. $\mathrm{O}$ aparelho visa também colaborar para a melhoria da prática educativa dos professores, promovendo o aperfeiçoamento, $\mathrm{o}$ enriquecimento do processo de ensino-aprendizagem.

Contudo, somente inserir o Tablet Educacional na escola, não garante a sua efetiva e produtiva utilização. Este cenário pode ser observado em uma escola integrante da Rede Estadual de Ensino, situada em uma cidade do interior do Estado de Minas Gerais. Os oito professores do Ensino Médio dessa instituição escolar, que receberam os tablets em meados de 2013, não estavam utilizando o aparelho. Os motivos principais averiguados foram: a falta de familiaridade com o equipamento, dificuldades para o seu manuseio e a não realização de uma formação para seu uso; sendo urgente e requerida pela escola uma formação para o uso desse instrumento.

Rocha (2008) afirma que as novas tecnologias inseridas no ambiente escolar precisam estar fundamentadas em um importante fator: boa formação dos professores, para agregar conhecimentos tantos técnicos como pedagógicos, primordiais para que se tenha sucesso na utilização de quaisquer equipamentos tecnológicos. Os professores, segundo Quaresma et al. (2014), precisam ter prioridade ao acesso às ferramentas e 
recursos tecnológicos, para que tenham a possibilidade de implementar novas propostas metodológicas e práticas inovadoras, promovendo a inclusão digital no âmbito escolar. Sendo assim, é preciso que os docentes estejam abertos às novas aprendizagens realizadas através das formações continuadas.

A formação contínua dos professores para o uso pedagógico das tecnologias é indispensável, uma vez que, a todo o momento, surgem novas possibilidades e, muitas vezes, os professores não estão preparados para utilização destas novas ferramentas digitais (BRUXEL, 2012). E a falta de informação sobre determinados recursos tecnológicos pode gerar a banalização dos mesmos, extinguindo seu uso antes mesmo de conhecer sua possível contribuição para o processo.

Nesse sentido, o objetivo desse estudo foi compreender a importância da formação contínua dos professores da escola em questão, como uma maneira de possibilitá-los a inserção das novas tecnologias digitais, nesse caso em específico o Tablet Educacional, às suas propostas pedagógicas. Para tanto, oferecemos uma formação aos oito professores do Ensino Médio dessa escola, de modo a apresentar as funcionalidades do Tablet Educacional, proporcionando-os conhecerem o aparelho e usufruírem dos seus benefícios e recursos.

\section{Metodologia}

A metodologia adotada foi a pesquisa-ação. Embasada nos princípios da abordagem qualitativa, a pesquisa-ação é uma modalidade de pesquisa realizada com o intuito de compreender um determinado fenômeno ou problema em seus aspectos constitutivos e propor alternativas de ação buscando saná-lo ou minimizá-lo (MIRANDA, 2012). De acordo com Thiollent (1986), na pesquisa-ação os pesquisadores e participantes desempenham um papel ativo, executando, de fato, ações, de modo cooperativo e participativo perante a situação em que estão envolvidos.

A pesquisa foi realizada durante o ano de 2015. Inicialmente, na fase exploratória e diagnóstica, identificamos a situação-problema, suas características, bem como suas implicações, para tanto, foram utilizados os instrumentos de coletas de dados: (i) observação, com a qual realizamos observações da ausência da hábitos dos professores na utilização dos Tablets Educacionais; e (ii) questionário, de modo a buscar a identificar a concepção dos professores em relação ao Tablet Educacional, dificuldades, facilidades em manusear o aparelho e as novas tecnologias digitais. $\mathrm{Na}$ fase de planejamento das ações foram elaboradas três ações interventoras (tabela 1), as quais, em seguida, foram desenvolvidas com os professores.

Ressaltamos que durante todo o processo investigativo - a fase exploratória e diagnóstica, o planejamento e desenvolvimento das ações - foram realizados de forma conjunta e colaborativa entre os pesquisadores, professores e a direção da instituição escolar. E ainda, cada fase da pesquisa foi permeada pela reflexão e avaliação de seus efeitos pelo grupo (MIRANDA, 2012). 
V Congresso Brasileiro de Informática na Educação (CBIE 2016)

Anais dos Workshops do V Congresso Brasileiro de Informática na Educação (CBIE 2016)

Tabela 1. Ações elaboradas e desenvolvidas na intervenção

\begin{tabular}{|c|c|c|}
\hline 1 $^{a}$ Ação & $2^{\mathrm{a}}$ Ação & $3^{\text {a }}$ Ação \\
\hline $\begin{array}{l}\text { Formação técnica para uso } \\
\text { do Tablet Educacional }\end{array}$ & $\begin{array}{l}\text { Formação pedagógica para } \\
\text { uso do Tablet Educacional }\end{array}$ & $\begin{array}{l}\text { Elaboração e desenvolvimento } \\
\text { de um plano de aula utilizando } \\
\text { o Tablet Educacional }\end{array}$ \\
\hline $\begin{array}{l}\text { Apresentação do aparelho, } \\
\text { suas funções, conexões, } \\
\text { configurações. Momento } \\
\text { de exploração e manuseio } \\
\text { do aparelho. }\end{array}$ & \begin{tabular}{lrr}
\multicolumn{2}{l}{ Aprentação dos } & aplicativos \\
instalados no & aparelho, em \\
especial, a & contribuição \\
pedagógica & do & Banco \\
Internacional de & Objetos \\
Educacionais $(\mathrm{BIOE})^{1}$.
\end{tabular} & $\begin{array}{l}\text { Com as devidas orientações, } \\
\text { elaboração e desenvolvimento } \\
\text { de um plano de aula, } \\
\text { propiciando a inserção do } \\
\text { aparelho na prática docente. }\end{array}$ \\
\hline
\end{tabular}

A primeira e segunda ação, a pedido da direção escolar, foram realizadas em um mesmo dia, em um encontro com sete horas de duração; e nas quatro semanas subsequentes, realizamos encontros semanais com duração de uma hora cada um, com o objetivo de esclarecer possíveis dúvidas. Posteriormente, desenvolvemos a terceira ação em um período de 15 dias. As três ações foram desenvolvidas nas dependências da instituição escolar.

A teoria e a prática, afirmam Lemes et al. (2011), devem "conversar" durante a formação do professor, as quais são aprendidas e assimiladas no decorrer do curso e na prática ligada ao ambiente escolar. E Lima, Lima e Maia (2015) destacam a importância da formação dos professores, para o uso das TIC, em seu local de trabalho, de modo a abordar e familiarizar os professores com essas tecnologias digitais. Quando a pesquisa é realizada no próprio ambiente onde as práticas ocorrem, na escola ou na sala de aula, afirma Miranda (2012), esses locais se transformam em "espaços de formação docente, de construção de novos saberes e práticas, mediada pela pesquisa-ação" (MIRANDA, 2012, p. 13).

\section{Resultados e Discussões}

\subsection{Fase exploratória e diagnóstica}

$\mathrm{Na}$ fase exploratória e a diagnóstica, verificamos que os professores não estavam utilizando os Tablets Educacionais que receberam, como já citamos anteriormente. Os motivos revelados, apontados pelos professores por meio de questionário, foram desconhecimentos das funções, recursos, possibilidades do aparelho e, principalmente, dificuldades de manusear tecnicamente o aparelho e a não realização de formação para o uso do aparelho. Prensky (2001) e Neves e Cardoso (2013), diante deste cenário, afirmam que muitos dos professores que estão atualmente em exercício na Educação, possuem grandes dificuldades para lidar com o novo aparato tecnológico, os quais a cada dia surgem e se inovam. Haja vista que, de acordo com Bévort e Belloni (2009), vários professores que atualmente lecionam, formaram-se em um período no qual não havia a propagação tecnológica na sociedade como no momento atual.

Assim, a formação continuada de professores, para o uso das novas tecnologias digitais, se tornou como importante meio de possibilitar a apropriação e utilização

\footnotetext{
${ }^{1}$ O Banco Internacional de Objetos Educacionais (BIOE) é um banco de Objetos Educacionais digitais, ou seja, recursos adicionais, de suporte, ao processo de ensino-aprendizagem de todos os níveis e áreas de ensino, em diferentes formatos, tais como: animação, áudio, vídeo, software, imagem e mapa (BALAN et al., 2010). O BIOE está disponível em: http://objetoseducacionais2.mec.gov.br/
} 
dessas tecnologias no ambiente escolar. Para Lévy (2007), essas formações precisam oferecer embasamento teórico e prático a estes profissionais, possibilitando-os construir diferentes metodologias, promovendo reflexões sobre a prática pedagógica, criando espaços de aprendizagem contextualizados e cooperativos.

Os professores da instituição escolar foram unânimes ao citar, mediante questionário que, primeiramente, é necessário haver uma formação; assinalaram que, sem uma formação eficiente, não conseguiriam utilizar o Tablet Educacional. Tendo em vista que não possuem conhecimentos prévios suficientes que os proporcionem tal ação. De acordo com Lévy (2007), é a formação contínua dos professores que irá determinar a integração eficiente dos novos equipamentos tecnológicos no ambiente escolar. A construção ou a ressignificação das competências e habilidades dos professores, afirma Martins (2009), tornou-se uma das principais âncoras para o sucesso do emprego dos equipamentos tecnológicos nas escolas.

Verificamos também, ainda pelo questionário proposto, que os docentes veem a necessidade crescente de se aproximarem da linguagem digital utilizada pelos alunos. Entretanto, é consenso dos professores que o principal empecilho enfrentado para utilizar o Tablet Educacional em sua prática docente diária é a dificuldade de manusear os novos equipamentos tecnológicos. Assim, segundo Passerino (2010), o que garantirá o uso adequado das ferramentas tecnológicas é o conhecimento acerca de suas funcionalidades e aplicações didático-metodológicas. Nesta perspectiva, de acordo Carneiro e Silva (2012), a inclusão digital e a formação continuada e permanente dos professores tornam-se fatores indispensáveis para $o$ acesso e a utilização dos equipamentos tecnológicos, os quais podem auxiliar de maneira significativa a educação escolar e o desenvolvimento de novas práticas pedagógicas.

\subsection{Fase de planejamento e desenvolvimento das ações}

As ações foram planejadas e realizadas de maneira a oferecer aos profissionais desta unidade educacional a possibilidade de conhecerem tecnicamente e se familiarizarem com o Tablet Educacional e, também, terem um contato com o aparelho como uma ferramenta educacional, instigando-os a inserir o tablet em sua rotina escolar.

Para se usufruir dos recursos que o Tablet Educacional pode oferecer é preciso que os professores saibam manipulá-lo operacionalmente. Sendo assim, a formação técnica faz-se necessária para que docentes consigam extrair do tablet seus benefícios e possibilidades. Além disso, também é fundamental que os professores saibam utilizá-lo pedagogicamente, com inovação e criatividade. $\mathrm{Na}$ formação de professores, de acordo com Souza (2006), a teoria e a prática devem se articular, constituindo-se como um todo. E colocando em prática os novos conhecimentos aprendidos na formação para uso do Tablet Educacional, segundo Nascimento (2014), os professores têm a possibilidade de obterem suporte ao seu trabalho pedagógico, bem como um avanço e uma inovação no contexto de sala de aula.

$\mathrm{Na}$ implementação da primeira ação, foi realizada a formação técnica para utilização do Tablet Educacional. Segundo Neves e Cardoso (2013), com a inserção do Tablet Educacional nas escolas da Rede Estadual de Ensino, surge a necessidade da oferta de formações continuadas para o uso significativo do aparelho, tanto tecnicamente como pedagogicamente. 
Assim, durante o desenvolvimento da primeira ação, os professores da unidade educacional tiveram a oportunidade de realizar o primeiro contato, formativo, com o tablet desde que o receberam. Por meio da formação realizada os professores conheceram melhor o aparelho, suas configurações, conexões e funcionalidades e, simultaneamente, conseguiram manipulá-lo por meio da realização das instruções e informações que eram transmitidas e discutidas.

De acordo com Rosalen e Mazzilli (2005), a formação técnica para uso de aparelhos eletrônicos é importante para se conhecer e esclarecer possíveis dúvidas e dificuldades que se possa ter em relação ao manuseio e o funcionamento de tais equipamentos. Neste sentido, no decorrer da formação com os professores, alvo desta pesquisa, os mesmos sanaram inúmeras dúvidas em relação ao aparelho, demonstrando muito interesse em aprender e em explorar o tablet ao máximo, de modo a permitir o uso produtivo e consciente do aparelho.

$\mathrm{Na}$ realização da segunda ação, houve a apresentação de orientações pedagógicas para utilização dos aplicativos disponíveis para o Tablet Educacional, já pré-instalados ou disponíveis para download, mais especificamente do Banco Internacional de Objetos Educacionais (BIOE). Segundo Valente (1998), as formações de professores devem, além de oferecer conhecimentos técnicos informacionais, apresentar técnicas de integração destes equipamentos da Informática na prática pedagógica.

Com o BIOE, segundo Balan et al. (2010), os docentes têm acesso a diversos recursos educacionais digitais que podem ser utilizados tanto na sala de aula como na preparação das aulas, como forma de enriquecimentos de sua prática pedagógica. Portanto, com o BIOE, os professores contam com uma importante ferramenta de auxílio ao processo de ensino-aprendizagem, com várias possibilidades de utilização, de modo a despertar o interesse dos alunos, permitir a contextualização e a interatividade com os temas trabalhados, além da possibilidade de proporcionar a interdisciplinaridade.

Após a formação técnica para uso do Tablet Educacional e a apresentação dos aplicativos/conteúdos disponíveis, com as respectivas orientações pedagógicas, os professores tiveram a oportunidade de inserir o aparelho em sua prática escolar, elaborando e desenvolvendo um plano de aula envolvendo-o e, posteriormente, registraram as experiências vivenciadas. Segundo Rosalen e Mazzilli (2005), somente a aplicação prática proporcionará a melhor fixação dos conhecimentos recebidos.

Verificamos que cinco professores utilizaram o tablet somente no planejamento da aula e os outros três no planejamento e desenvolvimento. Sobre os que utilizaram o aparelho na preparação da aula, percebemos que conseguiram realizar pesquisas, explorar o BIOE, acessar materiais para o enriquecimento de sua prática. Com relação aos professores que utilizaram o Tablet Educacional no desenvolvimento da aula, observamos que tiveram uma boa desenvoltura, fizeram download de aplicativos ou acessaram aplicativos/programas online, navegaram pela internet à procura de conteúdos para despertar e facilitar a aprendizagem dos seus alunos.

No registro das experiências vivenciadas com a utilização do Tablet Educacional, os professores que utilizaram o aparelho durante o desenvolvimento da aula informaram que a aula ficou mais atraente e que os alunos mais jovens ficaram mais interessados pela aula. Os alunos adultos, segundo os professores, a princípio 
foram mais receosos, mas conseguiram navegar pelas páginas do aplicativo e sites, e realizaram as atividades que foram propostas com o auxílio do tablet.

Em relação à motivação à incorporação e utilização do Tablet Educacional em sua prática docente, todos os professores responderam que pretendem utilizá-lo. "Fiquei muito motivada e pretendo utilizar o tablet em várias outras aulas", afirmou um dos professores. "Com o uso do tablet, atendendo às nossas necessidades e às dos alunos, será um grande passo para o sucesso do Ensino Médio", escreveu outro professor. "A partir dessa experiência, acredito que o tablet pode e deve ser um instrumento mais utilizado no processo de ensino-aprendizagem", respondeu outro professor.

Portanto, por meio das três ações realizadas na escola - formação técnica; formação pedagógica; e uma primeira experiência com o aparelho na elaboração de uma aula - percebemos que os professores conheceram melhor o Tablet Educacional e começaram a ver o equipamento como um novo recurso que pode auxiliá-los em suas práticas docentes diárias. Assim sendo, os professores participantes ficaram motivados diante da oportunidade de começar a utilizar o aparelho.

De modo geral, constatamos que os professores, na medida do possível, conseguiram ser bem sucedidos durante o desenvolvimento dessas ações. Contudo, ressaltamos que este foi parte de um processo contínuo para que os professores possam utilizar o aparelho no ambiente escolar, tendo em vista que este foi o primeiro contato formativo entre os professores dessa escola e o tablet. Concluindo, reafirmamos a necessidade de uma formação contínua e permanente, pois, como relatado por um dos professores, as dúvidas vão surgindo na medida em que se utiliza o aparelho e o sucesso de sua utilização dependerá do suporte dado neste momento.

\section{Considerações Finais}

Essa pesquisa revelou que os professores da unidade educacional lócus da pesquisa, não têm afinidade com os novos aparelhos digitais, apresentando inúmeras dificuldades com o manuseio desses novos equipamentos - um panorama totalmente inverso aos dos alunos, que possuem, geralmente, grandes habilidades com esse universo cada vez mais influenciado pelas novas tecnologias digitais.

Existe uma necessidade crescente das escolas e, consequentemente, dos profissionais da Educação, adequarem suas práticas pedagógicas a essa nova realidade, por meio da apropriação dos novos recursos digitais. Esses, segundo Neves e Cardoso (2013), deixaram de ser um diferencial no ambiente escolar e tornaram-se ferramentas de grande relevância na construção do conhecimento. Mas, para tanto, é preciso que os professores conheçam as potencialidades e tenham domínio da utilização dessas novas tecnologias digitais, sem se esquecerem de estar sempre pautados em um planejamento bem elaborado, para que o uso dessas ferramentas seja capaz de gerar bons resultados no processo de ensino-aprendizagem.

Neste contexto, o Tablet Educacional entregue aos professores do Ensino Médio, pode promover essa aproximação entre as novas tecnologias digitais e o processo educacional, auxiliando o trabalho dos professores, motivando-os a promoverem um ensino-aprendizagem mais participativo e cooperativo. Contudo, verificamos, por meio deste estudo, que os professores da unidade educacional em questão, não estavam utilizando o aparelho por desconhecerem suas funcionalidades e por não conseguirem manuseá-lo, pois não foi oferecido nenhum tipo de formação para estes profissionais. 
Então, com o desenvolvimento de três ações interventoras buscamos munir os professores: de conhecimentos técnicos, de modo a possibilitá-los manusearem e conhecerem o aparelho, suas características técnicas e operacionais; de conhecimentos pedagógicos, para que conheçam os aplicativos, conteúdos disponíveis, em especial o BIOE e as possibilidades de aliá-los a sua prática; e, também, proporcionar aos professores uma primeira inserção do aparelho, com as devidas orientações, em sua prática docente, propiciando-os colocarem em prática os conhecimentos adquiridos durante a formação e esclarecerem possíveis dúvidas que possam surgir durante o uso do aparelho. Dessa forma, os professores foram instigados a repensar suas práticas a fim de viabilizar o uso dessa ferramenta em favor de uma educação de mais qualidade.

Por meio dos planos de aulas elaborados, verificamos que os profissionais tiveram boa desenvoltura com o Tablet Educacional e conseguiram utilizá-lo. Realizaram pesquisas, acessaram conteúdos diversos e utilizaram o aparelho com os alunos, a partir da realização de atividades online. Os professores ainda relataram que pretendem continuar utilizando o tablet, mostrando que as ações desenvolvidas tiveram impacto positivo na prática pedagógica de cada profissional, levando-os a adquirir conhecimentos relevantes sobre o aparelho.

Assim, foi possível compreender, por meio do desenvolvimento das ações, a importância da formação contínua, permanente e eficiente de professores, com a participação ativa dos envolvidos, para o uso das novas ferramentas tecnológicas no ambiente escolar, neste caso em especial, o Tablet Educacional. Uma formação que ofereça conhecimentos técnicos e orientações pedagógicas, combinada com a motivação dos profissionais, pode ser de grande valia para se ter sucesso na utilização de novos equipamentos tecnológicos nas escolas.

Portanto, somente disponibilizar o acesso ao Tablet Educacional e oferecer capacitações rápidas, quando elas existem, não é o suficiente. A Informática oferece ferramentas importantes para a Educação, mas há um processo de implantação que pressupõe, primeiramente, a adoção de políticas públicas eficazes e contextualizadas, a formação contínua dos professores e das equipes pedagógicas, a adequada estruturação das escolas e, ainda, que essas medidas alcancem os alunos e suas comunidades.

\section{Referências}

BALAN, A. M. O. A. et al. (2010). Banco Internacional de Objetos Educacionais: uma ferramenta para auxiliar no processo de ensino-aprendizagem por meio do uso das Tecnologias de Informação e Comunicação. Encontro de Iniciação Científica, Presidente Prudente, v. 6, n. 6, p. 2-11, 2010.

BRASIL (2010). Inclusão digital. 2010. Disponível em: $<$ https://i3gov.planejamento.gov.br/textos/livro4/4.6_Inclusao_Digital.pdf $>$. Acesso em: 25 maio 2016.

(2012). Ministério da Educação. Ministério distribuirá tablets a professores do Ensino Médio. 2012. Disponível em: < http://portal.mec.gov.br/index.php?option=com_content\&view=article\&id=17479:mi nisterio-distribuira-tablets-a-professores-do-ensino-medio\&catid=215\&Itemid=164> . Acesso em: 12 maio 2016. 
V Congresso Brasileiro de Informática na Educação (CBIE 2016)

Anais dos Workshops do V Congresso Brasileiro de Informática na Educação (CBIE 2016)

BRUXEL, C. M. L. (2012). A Mídia Informática nos Anos Iniciais: possibilidades e desafios. 2012. 46 f. Monografia (Especialização) - Curso de Mídias na Educação, Universidade Federal do Rio Grande do Sul, Porto Alegre, 2012.

BÉVORT, E.; BELLONI, M. L. (2009). Mídia-Educação: conceitos, história e perspectivas. Educação e Sociedade, Campinas, v. 30, n. 109, p. 1081-1102, set./dez. 2009.

CARNEIRO, G. B.; SILVA, J. L. C. (2012). Políticas públicas de inclusão digital no contexto da educação escolar como fator de acesso a informação. In: ENCONTRO REGIONAL DE ESTUDANTES DE BIBLIOTECONOMIA, 15., 2012, Anais... Rio Grande. Rio Grande: EREDB, 2012. p. 1 - 11.

FUNDO NACIONAL DE DESENVOLVIMENTO DA EDUCAÇÃO (FNDE). Programas: ProInfo. Disponível em: $<$ http://www.fnde.gov.br/programas/programanacional-de-tecnologia-educacional-proinfo/proinfo-tablets $>$. Acesso em: 25 maio 2016.

LEMES, C. de M. et al. (2011). A teoria e a prática na formação de professores: desafios e dilemas. In: ENCONTRO ESTADUAL DE DIDÁTICA E PRÁTICA DE ENSINO, 4., 2011, Anais... Goiânia: EDIPE, 2011, p. 1-19.

LÉVY, P. (2007). Cibercultura. 2. ed. São Paulo: Editora 34, 2007. Tradução de Carlos Irineu da Costa.

LIMA, R.; LIMA, W.; MAIA, D. (2015). Formação Continuada de Professores para as TIC: Análise a Partir dos Cursos Ofertados pelo NTE-Natal. In: WORKSHOP DE INFORMÁTICA NA ESCOLA (WIE 2015), 21., 2015, Maceió. Anais do $21^{\circ}$ Workshop de Informática na Escola (WIE 2015). Maceió: SBC, 2015. p. 435 - 443.

MARTINS, C. A. (2009). Formação do docente de Matemática imigrante digital para atuar com nativos digitais no Ensino Fundamental. 2009. 116 f. Dissertação (Mestrado) - Curso de Educação em Ciências e Matemática, Pontifícia Universidade Católica do Rio Grande do Sul, Porto Alegre, 2009.

MIRANDA, M. I. (2012). Pesquisa-ação escolar: uma alternativa de enfrentamento aos desafios educacionais. In: MIRANDA, Maria Irene; SILVA, Lazara Cristina da (Orgs.). Pesquisa-ação: uma alternativa à práxis educacional. Uberlândia: EDUFU, 2012.

NASCIMENTO, F. R. F. M. do (2014). O uso pedagógico do Tablet Educacional como ferramenta de aprendizagem dos alunos do $1^{\circ}$ ano regular do Ensino Médio. 2014. 27 f. Monografia (Especialização) - Curso de Fundamentos da Educação, Universidade Estadual da Paraíba, Campina Grande, 2014.

NEVES, A. M.; CARDOSO, C. R. (2013). Os desafios do uso do tablet pelos professores do Ensino Médio das escolas públicas do Distrito Federal. In: COLÓQUIO INTERNACIONAL DE EDUCAÇÃO COM TECNOLOGIA, 01, 2013, Pernambuco. Anais eletrônicos. Pernambuco: UFPE, 2013. p. 1-22.

PASSERINO, L. M. (2010). Apontamentos para uma reflexão sobre a função social das tecnologias no processo educativo. Texto digital, Florianópolis, Universidade Federal de Santa Catarina, v. 6, n. 1, p. 58-77, 2010. 
V Congresso Brasileiro de Informática na Educação (CBIE 2016)

Anais dos Workshops do V Congresso Brasileiro de Informática na Educação (CBIE 2016)

PRENSKY, M. (2001). Digital natives, digital immigrants. On the horizon, Bradford, v. 9, n. 5, p. 1-6, out. 2001.

QUARESMA, C. R. T. et al. (2014). Tecnologias na Educação: inclusão digital dos professores da rede estadual a partir da implementação do programa Tablet Educacional. Tecnologias na Educação, Porto Alegre, v. 12, n. 1, p. 1-9, jul. 2014.

ROCHA, S. S. D. (2008). O uso do computador na Educação: a Informática Educativa. Espaço Acadêmico, Maringá, v. 8, n. 85, p. 1-6, jun. 2008.

ROSALEN, M.; MAZZILLI, S. (2005). Formação de professores para o uso da informática nas escolas: evidências da prática. In: REUNIÃO ANUAL DA ANPED, 28. Anais... Caxambu: UNIMEP, 2005.

SOUZA, D. T. R. de. (2006). Formação continuada de professores e fracasso escolar: problematizando o argumento da incompetência. Educação e Pesquisa, São Paulo, v. 32, n. 3, p. 477-492, set./dez. 2006.

VALENTE, J. A. (org.). (1998). Computadores e conhecimentos: repensando a educação. 2. ed. Campinas: Unicamp, 1998.

VELLOSO, F. de C. (2014). Informática: conceitos básicos. 9. ed. Rio de Janeiro: Elsevier, 2014.

THIOLlENT, M. (1986). Metodologia da pesquisa-ação. 2. ed. São Paulo: Cortez, 1986. 